\title{
From Wilderness to WildCountry: The power of language in environmental campaigns in Australia
}

\author{
Jenny Pickerill
}

Department of Geography, Leicester University, University Road, Leicester, LE1 7RH, 0116 252 3836,j.pickerill@leicester.ac.uk

[Final copy, $16^{\text {th }}$ March 2007]

\section{A wild language}

'Love the Wild? Help keep it Wild' (John Muir Trust flyer, 2006)

"Wild people (colonisers) make wild country (degrading, failing)" (Rose, 2004 p.4)

Environmental campaigns worldwide are often framed as conserving 'wilderness' and preventing exploitation of natural resources. Organisations lobbying for protection of vast tracts of Alaska, Canada, and Australia employ an emotive language using words such as 'pristine', 'untouched', 'undisturbed', 'intact expanse' and 'wild frontiers' to rally support. Photographs of lands empty of people or any human structures often accompany these words, see Figure 1. This approach has proved successful in arguing for the need to place legal boundaries around tracts of land through World Heritage Status or as National Parks.

\section{Figure 1: The Wilderness Society's Wild Country logo}

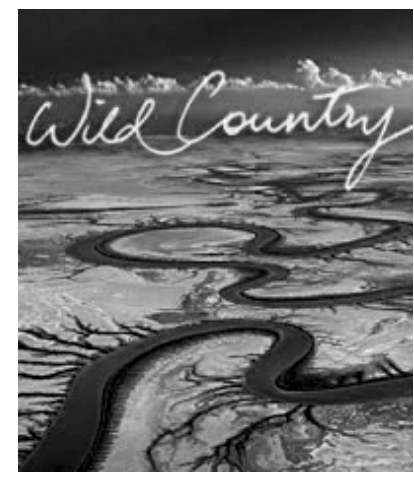

Despite this, there is increasingly recognition not only that indigenous people have historic rights of possession to some of that land, but also that indigenous environmental knowledge and land management practices can be beneficial for conservation outcomes. This recognition and the legal changes that have accompanied it (such as the development of Native Title in Australia) have forced environmental and conservation groups to reconsider their approach. Simultaneously a global movement has emerged focused on environmental justice and environmental racism. Yet this operates in tandem and separate from those groups concerned with biodiversity and wildlife preservation. Many environmental groups have been slow to change their language or practices when it comes to viewing areas as 'wilderness' devoid of people, cautious of meddling with their model of success and entering the complex and contested arena of indigenous politics.

There are many reasons to urge such groups to change: such practices are a continuation of an unjust colonial system complete with racism and stereotypes; they not only fail indigenous 
populations but lead to the loss of valuable environmental knowledge; and academics have long called for the need for a more nuanced understanding of nature - not viewing it as a separate entity from social and cultural influences (Castree, 2003). Moreover, while progress at the global level through UN resolutions to ensure that indigenous people are not forcibly removed from their lands has been slow, small changes can occur at a local scale with positive effects for indigenous communities. In other words, environmental groups have the power and capacity to markedly improve the situation for the betterment of conservation outcomes and indigenous people.

This article explores the problems of the term 'wilderness', why it is still employed and how indigenous communities would rather that their land was understood. Using examples from Australia it then examines two different ways that environmental groups have sought to move forward. Material was collated through thirty in-depth interviews with indigenous and nonindigenous activists in Queensland and Victoria. Throughout the paper the term 'land' is taken to include sea and coastal areas, and the distinction between indigenous and nonindigenous people is used. Although this is a crude separation it is based upon the language commonly used by those interviewed for this piece both as self-definition and in defining the identity of others. Indigenous identity is a complex and contested arena of which there is insufficient space to address here.

\section{Wilderness and country}

Language is a key articulation of power in understandings of the 'environment'. The term 'wilderness' and its relation 'wild' is highly problematic when talking of any landscape but especially so in Australia, a land inhabited by the indigenous population for tens of thousands of years. Yet these terms are still employed. Such a romanticisation of the environment draws upon the writings of Henry David Thoreau, John Muir, and Miles Dunphy, and are used to sell Australia and garner support for environmental protection. For The Wilderness Society the term is important though problematic. Their constituents value 'wilderness' and
"getting people to support environmental protection is in part an appeal to these values ... and it results in public and political support for the preservation of large, remote, intact areas. These areas have extraordinary natural and Indigenous cultural values. They are fully functioning ecosystems which are becoming rare globally and are important to protect if we are to meet the conservation imperatives of the 21 st century. But these are also areas in which Indigenous people retain title and interests ... When we undertook focus group work on this topic, public supporters of environment protection became much more uncomfortable, much more tentative; the environmental, social and economic issues much more complex to resolve ... So to win the support of this group, who happen to be very important in electoral terms and therefore important to outcomes in public policy, we have to carefully resolve these issues and bring about attitudinal change ... unfortunately there is still latent colonialism among some sections of the community, which is a political factor to be dealt with" (Anthony Esposito, National Indigenous Program Manager, TWS, interview)

Indigenous people have been highly critical of the use of such a word. It has obvious colonial and racist connotations, "the term 'wilderness' in itself is an expression of terra nullis you're maintaining the argument that we don't exist - there was never a wilderness in Australia - it was an inhabited landscape" (Gary Foley, interview). Even without this history 
the word 'wild' for indigenous people means a human-made land where nothing grows and where life is absent. Thus "“wildness' is country that has gone bad" (Dermot Smyth, Consultant and affiliated to James Cook University, Cairns, interview). Contemporary nonindigenous interpretations of wilderness tend to celebrate it as life unlimited, a place of sublime experiences and sacred (Cronon, 1995). In fact, when we have an understanding of how wilderness has been socially constructed throughout history we find ample examples of wilderness being perceived as something "to be feared, an area of waste" (Short, 1991, p.6) prior to the period of the romantics. Thus in the early years of the non-indigenous settlement of Australia, nation-building was explicitly about taming the wilderness and consequently rendering the land 'civilised', ordered and productive - imposing a very British vision of what constituted nature and landscape. Revealingly, the word 'bewildered' has it roots in this fear that wilderness could corrupt the human psyche, cause spiritual despair and ultimately leave a person at loss and lacking direction. More recently contemporary city spaces have been labelled wild by non-indigenous observers for "the most desolate wilderness is the one we could create ourselves" (Short, 1991, p.27).

Arnold Wallis (Chairperson of the Wuthathi Tribal Council, Cairns, interview) noted the irony in using such terms: "aboriginal people are not savages, they just have a different perspective on life - it's called 'leave your environment as it is, don't get barbaric about it and bulldoze it down'. We consider those sorts of practices fairly wild - how barbaric to destroy the very essence that maintains you in your culture and your society". Here he is criticising Australian policy more than environmental groups use of language per se, but he also speaks of the ways such language places a hierarchy on the value of land, so that those areas deemed less 'wild' are viewed as of less value (and can thus be bulldozed) regardless of their importance to traditional owners. For those indigenous communities struggling to protect and manage their land this can be frustrating. Neil Martin of Framlingham Aboriginal Trust spoke, during an interview, of his lack of success in getting environmental groups interested in a newly formed Indigenous Protected Area in Victoria: "they've been out there and had a look. I think they were disappointed. They didn't say it but I think they were because they were expecting grandiose unimpacted sceneries. ... we haven't had any success with them". Thus, as Cronon (1995) notes, "wilderness tends to privilege some parts of nature at the expense of others ... of the nature that is all around us if only we have the eyes to see it" (p.86).

This narrow vision of what 'wilderness' entails which has in the past been propagated by environmental groups is dualistic ${ }^{i}$. Indigenous Australians argue that there can be no such division between the environment and culture because they "are one and the same, they coexist and are not separate" (Melissa George, a Wulgurukaba woman and Traditional Owner). Thus "land is a much more energetic configuration of earth and air, water and minerals, animals and plants, as well as people than a surface area contained by lines on a map" (Whatmore, 2002, p.71). These differences are reflected not only by the rejection of the use of 'wilderness' but by the active use of the word 'country'. Country is viewed as an intertwining of kinship, ancestry, and responsibility (Langton, 1998). Thus it is intimately linked into indigenous identity and as Arnold Wallis said "to us it's home".

Perversely, non-indigenous understandings celebrate 'wilderness' because it is 'out there'. Ignoring the history of inhabitation, of forced removal, and of the social construction as to what counts as a valid 'wild' landscape, this approach cherishes what is separate and detached from home. It is in part celebrated because it is absent from daily life. But this leads to an ideological dead-end; "if wild nature is the only thing worth saving, and if our mere presence destroys it, then the sole solution to our own unnaturalness, the only way to protect sacred 
wilderness from profane humanity, would seem to be suicide" (Cronon, 1995, p.83). Thus the non-indigenous conceptualisation of 'wilderness' prevents any meaningful discussion of how humans can have any place in nature. So bound up, as it is, in saving scared spaces from the destructive forces of civilisation and thus treating 'wilderness' as the Other, that it treats indigenous people as Other as well and fails to acknowledge the potential of perceiving of all areas - cities and wilderness - as 'home'.

Moreover there is an indigenous responsibility to land, "we don't own that land ... we belong to that country, it owns us. We therefore have a responsibility to care for it, manage it, maintain it, nurture it and do all that we can to make sure that it's sustainable for future generations" (Arnold Wallis, interview). Precisely because of these interrelations between environment and culture indigenous people need to live on their land in order to care for their country; "the land needs the people and the people need the land ... these are important cultural environments that require people to manage them according to tradition and culture, to maintain ... and to encourage species" (Damian Britnell, Chief Executive Officer, Bamanga Bubu Ngadimunku Inc, Mossman Gorge Aboriginal Community, interview).

\section{Moving forward or new forms of control?}

The indigenous critique of 'wilderness' and approach to 'country', especially calls to live on land, is thus controversial. It reveals the different ontologies (what we know to exist) and epistemologies (the structures of knowledge by which we know what exists) of indigenous and non-indigenous Australians (Suchet, 2002). Moreover, it challenges the dominant narrative of sustainable development. In his examination of Australian environmental imaginaries McGregor (2004) identified the dominant view of nature as a resource requiring better scientific management rather than as holding intrinsic value. This approach "delegitimises non-rational approaches to nature, disempowering them within the environmental imaginary and opening them to ridicule" (McGregor, 2004, p.603). Consequently non-dualistic discourses are marginalised, further diminishing the opportunity for understanding indigenous approaches.

In this context environmental groups could be forgiven for being weary of attempting to incorporate indigenous perspectives into their campaigns. Some environmentalists still see engagement with indigenous issues as an unnecessary diversion from the main task of environmental protection. James McLellan (Co-ordinator of North Queensland Conservation Council, Townsville) argued "I just don't think, on the scale of impacts that we're fighting, that they're [traditional owners] high enough up the curve for us to actually be putting very much capacity into it ... I don't see it as necessary for us ... to spend an atrocious amount of time and money doing indigenous stuff - I've yet to see any benefit from it" (interview). However, the majority of environmental groups in Australia now have (albeit it often only very recently) a vague policy of supporting indigenous rights. Some groups have attempted to go further and alter their language and practices to implement this policy. The Wilderness Society (TWS) and the Australian Conservation Foundation (ACF) are both high profile national environmental organisations who have taken different approaches to the issue of 'wilderness' and indigenous perspectives.

The Wilderness Society has an obvious problem - its name. It has recently adopted the term 'WildCountry' to encapsulate a new approach towards conservation. Lyndon Schneiders, the Cape York and Far-North Australia Campaigner for TWS, hoped that this might help the organisation move away from the debate about 'wilderness'; "that's why we dubbed it WildCountry - it was an attempt to keep the best of the idea and the movement of essentially the white folk that are supporting the stuff in southern Australia, at the same time recognising 
that in northern Australia there is no wilderness" (interview). The continued reference to 'wild' has met with criticism. Arnold Wallis commented "how stupid of them to say it's a wild country - how dare they do it because it has some connotations", but he went on to suggest that the term also provided an opportunity "for us it became a political tool to bring about some awareness that indigenous people don't consider this wild country". Moreover, "there has been a profound realignment taking place in the concept of wilderness and in the approach and policies of the Wilderness Society in Australia ... in part driven by the advent of native title in the Australian legal system, and in part by the critiques by Indigenous leaders of the values associated with traditional wilderness ideals" (Anthony Esposito, interview).

In practice TWS have shifted away from large-scale agreements and broad alliances with indigenous groups to grounded community level cooperation. This approach appears more successful. Although they have not discarded the contentious goal of creating National Parks, they are working more in collaboration with traditional owners, supporting their attempts to gain Aboriginal Freehold land and establish Indigenous Protected Areas (Schneiders, 2006, p.27). They are developing 'tenure-blind' conservation measures less concerned with who owns the land and more focused on good land management practices. Most recently they have begun to build co-operation agreements with southern Australian Indigenous organisations.

TWS remain clear that their main goal is environmental preservation not indigenous advocacy, they have made mistakes and they have not mollified all their (especially indigenous) critics. However, one thing is clear, a commitment to moving forward. Kerryn O'Conor, the TWS North Queensland Campaigner, emphasised that they will continue to do that even if it means working around their existing language, "there's a lot of work we need to do around the language, but you can get around language when you actually start talking about context and talking about values and talking about outcomes, and if you can find the commonalities in that kind of dialogue, then the language to me is secondary" (interview).

The Australian Conservation Foundation have taken a different path. They have instigated a Northern Australia Programme which aims to be a long term proactive approach towards creating a bi-cultural organisation. It is focused on jointly coming up with goals rather than finding campaign partners for issues they think are important. To this end ACF have even opposed the creation of new National Parks when traditional owners have objected because they prioritised "genuinely respecting those alliances" (Don Henry, Executive Director of ACF, interview). For many years they have employed Indigenous Policy Officers and as such, "ACF is trying to find that middle ground between indigenous people and their connection to country, their rights around country, obligations to country ... and environmental responsibilities in terms of protection and restoration and sustaining the environment" (Leah Talbot, Cape York Project officer for the Northern Australia Program, interview). In terms of language ACF avoid the words 'wilderness' and 'biodiversity' all together and instead "we talk about nature and culture - natural and cultural values and the link between the two and people, so that's why our leaflet says 'nature, culture, people"' (Rosemary Hill, Northern Australia Program Coordinator and ACF Councillor, interview) (see Figure 2). Yet ACF are surprisingly quiet about the indigenous aspects of their work, perhaps cautious of being seen to use their indigenous engagement as a marketing tokenism or acknowledging that there is still much work to be done. 
Figure 2: An Australian Conservation Foundation flyer

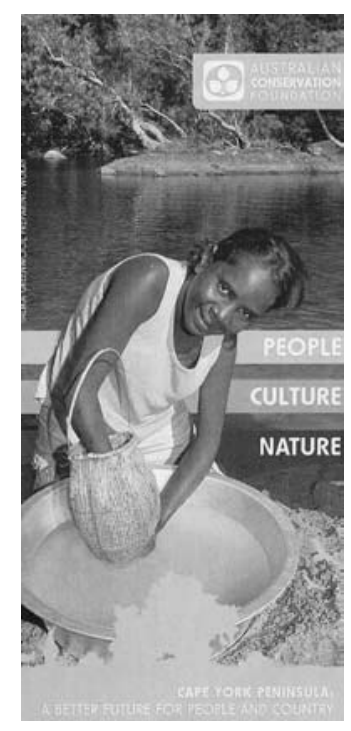

In reflecting upon changing Australian conservation approaches Figgis (2003), previously a Vice President of the ACF, seeks to embrace the diversity of conservation models now emerging. However, she expresses a fear that these approaches will ultimately dilute the security of the traditional sanctuary model maintaining that "wild places are an irreplaceable and essential part of nature conservation" (p.216). Figgis expresses a concern that indigenous groups have emphasised their rights to economic development, and while acknowledging the moral imperative for engaging with indigenous issues, reveals a more strategic reason for such interaction, "title to an estimated 14 per cent of Australia - an area of more than 1 million square kilometres - has been restored to Aboriginal people. Significantly, this is over twice the area currently in protected areas, ... any truly comprehensive reserve system would need to include components of these lands" (p.202).

Both these organisations have made progress in modifying their language and practices in response to the charge that they were party to "a form of ecological imperialism" (Langton, 1998, p.18). However, two key problems remain. Firstly, the majority of indigenous engagement by these two groups has been confined to northern Australia (bar recent TWS collaborations in southern Australia). There remains a north-south division within the Australian environmental movement with a perception that indigenous consultation is only a necessity in the north. A view persists that there is no need to engage with indigenous politics further south perpetuating the myth that only those indigenous people who have a more apparent and historic (according to non-indigenous adjudicators) connection to their homeland need consultation. Others are somehow 'cultureless' reinforcing the construction of an 'authentic' 'traditional' indigenous person against which indigenous identity is judged (Adam and English, 2005). Thus despite good work continuing on the ground in parts of Queensland until this is reflected and supported by those in the higher ranks of the respective organisations, in national polices and attempts to educate the Australian public, such organisations contribute to the broader constraints placed on indigenous people by others defining who they are and what they can become. As acknowledged by Anthony Esposito, given the conservatism of environmental groups support base, this shift is unlikely to happen any time soon.

Secondly, although the language has changed the underlying premise of why a landscape is of enough value to protect has not altered. ACF has gone further than TWS by including 'people' in their language, but both still employ a bio-physical based and scientific method to 
determine value, and both still prioritise environmental protection. We are a long way from bridging the gap between 'environment' and 'culture' and widening the ways in which we value landscape. Environmentalists are right to be fearful of diluting what preservation gains they have made, especially in the current Australian political climate. Nor is this paper arguing that there is no environmental and social value in protecting 'wilderness' areas. However, we should use these areas to encourage more people to value and respect all natures and people; "we need to honor the Other within and the Other next door as much as we do the exotic Other that lives far away - a lesson that applies as much to people as it does to (other) natural things" (Cronon, 1995, p.89). Thus we need to celebrate 'wilderness' not so much for its bio-physical qualities but for what it can teach us about ourselves, our history, how we treat Others, and the nature all around us.

This process of questioning, listening, changing and moving forward remains difficult for all involved. More mistakes will be made, more terms used and then discarded, and practices will evolve through trial and error. It is crucial that we have a sense of history and understanding of the social construction of 'wilderness'. Yet it is also clear that these experimental processes must continue. We must hope that moments of mutual understanding will be reached and that "maybe tomorrow, we will all sit in the circle of life, same rhythm, same time" (Pryor, 1998, p.201).

\section{Acknowledgements}

This research was undertaken through funding provided by The British Academy (SG-38399). This paper would not have been possible without the invaluable help of all the interviewees. Particular thanks go to Anthony Esposito who gave insightful comments on an earlier version of this work.

\section{References}

Adams, $M$ and English, A (2005) ' Biodiversity is a whitefella word': Changing relationships between Aborigines and the New South Wales National Parks and Wildlife Service' pp.86-97 in L.Taylor, G.K.Ward, G.Henderson, R.Davis and L.A.Wallis, The Power of Knowledge, the Resonance of Tradition, Aboriginal Studies Press, Canberra.

Castree, N (2003) 'A post-environmental ethics?' Ethics, Place and Environment, 6, 1, pp.312.

Cronon, W (1995) 'The Trouble with Wilderness; or, Getting Back to the Wrong Nature' in W.Cronon (ed.) Uncommon Ground: Rethinking the Human Place in Nature. W.W.Norton and Company, New York, p.69-90.

Figgis, P (2003) 'The changing face of nature conservation: Reflections on the Australian experience' in W.M.Adams and M.Mulligan (eds.) Decolonizing Nature: Strategies for Conservation in a Post-colonial Era. Earthscan Publications, London, p.197-220.

Langton, M (1998) Burning Questions: emerging environmental issues for indigenous peoples in northern Australia. Centre for Indigenous Natural and Cultural Resource Management, Northern Territory University, Darwin.

McGregor, A (2004) 'Sustainable development and 'warm fuzzy feelings': discourse and nature within Australian environmental imaginaries Geoforum 35, 593-606.

Pryor, B (1998) Maybe Tommorrow. Penguin.

Rose, D, B (2004) Reports from a Wild Country: ethics for decolonisation. University of New South Wales Press, Sydney.

Schneiders, L (2006) 'Is Wilderness Racist?' Chain Reaction, Autumn, p.25-7.

Short, J, R (1991) Imagined Country: Environment, Culture and Society. Routledge, London

Suchet, S (2002) 'Totally Wild'? Colonising discourses, indigenous knowledges and managing wildlife' Australian Geographer, 33, 2, pp.141-157. 
Whatmore, S (2002) Hybrid Geographies. Routledge, London.

${ }^{\mathrm{i}}$ There are environmental groups in Australia, such as Friends of the Earth, who have long employed a more nuanced approach to the complexity of environmental issues - seeking to place humans alongside environmental concerns, thus marrying social and environmental justice as their goals. However, such groups remain small and thus their impacts limited in scale, leaving the bigger national environmental organisations to dominate public debates and perceptions of 'wilderness'. 